\title{
Silicon-Encapsulated Hollow Carbon Nanofiber Networks as Binder-Free Anodes for Lithium Ion Battery
}

\author{
Ding Nan, ${ }^{1,2}$ Zheng-Hong Huang, ${ }^{1}$ Ruitao Lv, ${ }^{1}$ Yuxiao Lin, ${ }^{1}$ Lu Yang, ${ }^{1}$ Xiaoliang Yu, \\ Ling Ye, ${ }^{1}$ Wanci Shen, ${ }^{1}$ Hongyu Sun, ${ }^{1}$ and Feiyu Kang ${ }^{1,3}$ \\ ${ }^{1}$ Key Laboratory of Advanced Materials (MOE), School of Materials Science and Engineering, Tsinghua University, \\ Beijing 100084, China \\ ${ }^{2}$ School of Materials Science and Engineering, Inner Mongolia University of Technology, Hohhot 010051, China \\ ${ }^{3}$ City Key Laboratory of Thermal Management Engineering and Materials, Graduate School at Shenzhen, Tsinghua University, \\ Shenzhen 518055, China
}

Correspondence should be addressed to Feiyu Kang; fykang@mail.tsinghua.edu.cn

Received 28 February 2014; Accepted 12 April 2014; Published 3 June 2014

Academic Editor: Jinlong Jiang

Copyright (C) 2014 Ding Nan et al. This is an open access article distributed under the Creative Commons Attribution License, which permits unrestricted use, distribution, and reproduction in any medium, provided the original work is properly cited.

Silicon-encapsulated hollow carbon nanofiber networks with ample space around the Si nanoparticles (hollow Si/C composites) were successfully synthesized by dip-coating phenolic resin onto the surface of electrospun Si/PVA nanofibers along with the subsequent solidification and carbonization. More importantly, the structure and Si content of hollow Si/C composite nanofibers can be effectively tuned by merely varying the concentration of dip solution. As-synthesized hollow $\mathrm{Si} / \mathrm{C}$ composites show excellent electrochemical performance when they are used as binder-free anodes for Li-ion batteries (LIBs). In particular, when the concentration of resol/ethanol solution is $3.0 \%$, the product exhibits a large capacity of $841 \mathrm{mAh} \mathrm{g}^{-1}$ in the first cycle, prominent cycling stability, and good rate capability. The discharge capacity retention of it was $\sim 90 \%$, with $745 \mathrm{mAh} \mathrm{g}^{-1}$ after 50 cycles. The results demonstrate that the hollow $\mathrm{Si} / \mathrm{C}$ composites are very promising as alternative anode candidates for high-performance LIBs.

\section{Introduction}

To meet the increasing demands of rapidly developing market from cell phone to electric vehicles for the Li-ion batteries (LIBs), new anode materials with higher capacity have attracted significant attention. Graphite, the most commonly used commercial anode material, has low theoretical specific capacity $\left(372 \mathrm{mAh} \mathrm{g}^{-1}\right)$ and poor rate capability. Silicon is considered as one of the most attractive and promising alternative anode materials to replace graphite in LIBs in the coming decades in virtue of its fascinating performance, such as relatively low working potential $\left(\sim 370 \mathrm{mV}\right.$ versus $\left.\mathrm{Li} / \mathrm{Li}^{+}\right)$, rich abundance in earth, environmental benignity, and especially the highest theoretical capacity of $4212 \mathrm{mAh} \mathrm{g}^{-1}$ among the existing anode materials [1]. However, there still exist several challenges which restrict the commercialization of such silicon anodes. Firstly, the large volumetric expansion $(\sim 400 \%)$ of silicon anodes upon the lithiation results in high internal stress, causes mechanical fracture and pulverization of electrode and subsequent losses of electrical contact between the active material and current collector, and leads to poor reversibility and rapid fading of capacity. Secondly, the huge and repeated volume change during the charge/discharge process prevents the formation of a layer of stable solid electrolyte interface (SEI). Hence it can easily continuously grow through the cracks till being too thick for Li-ions to diffuse through, and in turn results in a low Coulombic efficiency and a decrease in capacity. Moreover, silicon anodes possess poor electrical conductivity $[2,3]$. Such drawbacks lead to serious capacity fade during cycles and thus hinder the practical applications of silicon anodes.

In order to address abovementioned challenges, it would be crucial to release the mechanical strains, as well as reducing the diffusion length of Li-ions in Si electrode materials during charge/discharge process. Nanostructured Si would be a good solution. So far, many nanostructured silicon 
and $\mathrm{Si}$-based composites with various morphologies, such as nanoparticles [4-10], porous nanoparticles [11, 12], nanofilm [13-18], nanotubes [19-21], nanofibers [2, 22-37], and coreshell structures [3, 38-42] have been prepared and evaluated. Among them, one-dimensional (1D) nanostructured Si or Sicontaining nanotubes, nanofibers, and core-shell structures showed very good electrochemical performance in virtue of the enhanced electric conductivity of the $1 \mathrm{D}$ nanostructures. Furthermore, they could easily form three-dimensional (3D) interconnected networks to buffer the huge volume changes of active $\mathrm{Si}$, thereby preventing the degradation of the electrode integrity and the breakdown of electric conductive networks. However, such $1 \mathrm{D}$ silicon nanostructures were usually synthesized by using toxic $\mathrm{SiH}_{4}$ as silicon precursor and costly Au particles as catalysts [22, 24, 39, 40]. Moreover, the synthesis of them seemed to be too elaborate and suffered from low yield. Thus, the most straightforward and practical approach recently to overcome these shortcomings is to directly utilize the commercially available $\mathrm{Si}$ nanoparticles incorporated into carbon matrix, for example, carbon nanofibers via electrospinning method [26-29, 3134]. Such products are typical interconnected nonwoven nanofiber networks with good mechanical integrity. The as-prepared free-standing fabrics can be directly used as anodes for LIBs without adding any other polymeric binders or conductive additives. They could increase the effective electrode-electrolyte interface area, facilitate the high-speed electron transport, and hold great potential to enhance the electrochemical performance. Nevertheless, in fact, their cycle stability is still inferior because the direct contact of carbon with silicon has the limited buffer capability, which is difficult to cope with about $400 \%$ of volume expansion.

More recently, to improve the cycling stability of silicon anode materials, some new nanostructures with $\mathrm{Si}$ nanoparticles encapsulated in continuous hollow carbon tubes have gained much attention due to the enhanced electrical conductivity and stable solid electrolyte interface (SEI). Moreover, particularly, the ample empty space inside the hollow tubes among the silicon nanoparticles allowed for silicon nanoparticles expansion freely during electrochemical cycling, supporting a stable cycling of the entire electrode as well as high charge and discharge rates [2, 3, 35-37, 42]. In addition, it is known that the low-cost phenolic resin (i.e., resol) has high carbon yield (over 50\%) during carbonization and good anodic performance for LIBs by exhibiting a high reversible capacity of $550 \mathrm{mAh} \mathrm{g}^{-1}$ [43]. More importantly, the resol could be solidified by occurrence of polycondensation reaction thus keeping the original morphology by means of solidification process. It is very favorable to generate the tubular nanostructure.

With a motivation to further increase the cycling stability of the silicon anode materials, in this work, we put forward a facile strategy to synthesize novel silicon-encapsulated hollow carbon nanofiber networks with ample space around the Si nanoparticles (hollow Si/C composites) by dip-coating resol on the surface of electrospinning Si/PVA nanofibers along with the subsequent solidification and carbonization. These freestanding membranous hollow $\mathrm{Si} / \mathrm{C}$ composites can be used directly as anodes for LIBs without adding any carbon conductors or polymer binders. The as-prepared hollow $\mathrm{Si} / \mathrm{C}$ composites display a high electrochemical performance with excellent cycle stability of $\sim 90 \%$ of discharge capacity retention after 50 cycles.

\section{Experimental}

2.1. Materials Synthesis. Firstly, polyvinyl alcohol (PVA, molecule weight $=80000)$ and deionized water were mixed in the ratio of $15 \mathrm{~g}$ PVA/135 $\mathrm{g}$ water. The mixture was stirred in water bath at $90^{\circ} \mathrm{C}$ for $2 \mathrm{~h}$ to form a homogenous solution. Meanwhile, silicon nanoparticles ( $\mathrm{n}-\mathrm{Si}, 0.04 \mathrm{~mol}$, average particle size of $80 \mathrm{~nm}$ ) were dispersed in deionized water $(10 \mathrm{~mL})$ with sodium linear alkylbenzenesulfonate by ultrasonication and magnetically stirred for $2 \mathrm{~h}$. Then, the suspension and the former solution were mixed and agitated for $12 \mathrm{~h}$ to be used for the precursor of electrospinning for $\mathrm{Si} / \mathrm{PVA}$ nanofibers.

A needle, with the inner diameter of $1 \mathrm{~mm}$, was connected to a high voltage DC power and vertically clamped on an insulating glass stick. A piece of graphite paper was used as the collector. The height of the needle and the distance between the needle and the collector were adjustable. Typically, $20 \mathrm{kV}$ of high positive voltage was adopted and the distance between the needle and collector was $15 \mathrm{~cm}$. The precursor solution was electrospun into fiber networks at a constant flow rate of $1.0 \mathrm{~mL} \mathrm{~h}^{-1}$. Then the Si/PVA nanofibers fabric was dipped into resol (thermosetting phenolic resin, molecule weight $=2080$ )/ethanol solution for 5 seconds to obtain the Si/PVA-Resol composites (abbreviated as Si/PVAResol- $n$ in text, $n$ represents concentration of resol/ethanol solution (\%)). Afterwards, the as-prepared Si/PVA-Resol composites were treated in air by a typical solidification process and then carbonized in Ar at $600^{\circ} \mathrm{C}$ for $1 \mathrm{~h}$ with a heating rate of $5^{\circ} \mathrm{C} \mathrm{min}^{-1}$ to finally acquire the siliconencapsulated hollow carbon nanofiber networks (i.e., hollow $\mathrm{Si} / \mathrm{C}$ composites, denoted as $\mathrm{H}-\mathrm{Si} / \mathrm{C}-n$, where $n$ represents the concentration of resol/ethanol solution (\%)). The solidification process was performed according to a stepwise heating curing process, that is, the reaction time shortened with increasing temperature, while the low temperature reaction held for a long time. The total cure duration was about $25 \mathrm{~h}$ when heating the samples in air from room temperature up to $180^{\circ} \mathrm{C}$.

\subsection{Materials Characterization and Electrochemical Evalua-} tion. The morphology and microstructure of samples were characterized using a scanning electron microscope (SEM, LEO 1530, Germany) and a transmission electron microscopy (TEM, JEOL 2010, Japan). Raman spectroscopy (Renishaw Invia RM200, England) was employed to study the structure of Si/PVA nanofibers. X-ray powder diffraction (XRD, Rigaku D/Max 2500PC, Japan) was used to characterize the crystal structures of the Si/PVA nanofibers and hollow Si/C composites. Thermogravimetric analysis (TGA) was performed to ascertain the carbon yield and Si content of samples on a TA instrument SDT-Q600 with temperature increments of 
$10^{\circ} \mathrm{C} \mathrm{min}^{-1}$ in Ar and air atmosphere. The specific surface area of samples was evaluated by $\mathrm{N}_{2}$ adsorption measurement on a Belsorp Max apparatus (Japan) and determined by Brunauer-Emmett-Teller (BET) method.

The electrochemical performance was characterized by galvanostatic cycling and cyclic voltammetry at room temperature in a half cell, in which lithium foil was used as the counter electrode and $1 \mathrm{M} \mathrm{LiPF}_{6}$ was dissolved in a mixture of ethyl carbonate (EC) and dimethyl carbonate (DMC) $(1: 1, \mathrm{v} / \mathrm{v})$ as the electrolyte. The samples were used as working electrode directly without adding any nonactive materials such as polymer binders or electronic conductors. Celgard 2400 was used as separator. The test cells were galvanostatically cycled between $0.01 \mathrm{~V}$ and $1.5 \mathrm{~V}$ versus $\mathrm{Li}^{+} / \mathrm{Li}$ to evaluate the electrochemical performance (LAND battery tester, Wuhan Jinnuo Electronics Co., Ltd.). Cyclic voltammetry was measured between $0.01 \mathrm{~V}$ and $1.50 \mathrm{~V}$ versus $\mathrm{Li}^{+} / \mathrm{Li}$ at a scan rate of $0.1 \mathrm{mV} \mathrm{s}^{-1}$ by an electrochemical workstation Im6ex (ZAHNER, Germany).

\section{Results and Discussion}

3.1. Materials Characterization. The strategy to design and fabricate the silicon-encapsulated hollow carbon nanofiber networks is schematically illustrated in Figure 1(a). Three simple yet critical steps are adopted in the present strategy. Firstly, the Si/PVA nanofibers to form Si-containing hollow tubular cavity were prepared using electrospinning and the morphology of them is present in Figure 1(b). It can be seen that Si/PVA nanofibers exhibit interconnected nonwoven nanofibrous structure. They have smooth, clean surfaces with diameters varying from tens to hundreds of nanometers and length of hundreds of microns. Such a high aspect ratio may provide considerable specific surface area for high mass uptake of resol deposits. Secondly, the Si/PVA-Resol composites were prepared by dip-coating a layer of resol onto the surface of Si/PVA nanofibers. To modulate the mass loading of resol deposits on the Si/PVA nanofibers surface, different concentrations of resol/ethanol solutions were undertaken to dip. As expected, it is clearly seen from Figure 1(c), by increasing the concentration of resol/ethanol solution, that the color of Si/PVA-Resol composites gets darker after solidification, indicating the increase of loading amount of resol. In addition, it is worthwhile to point out that, just after 5 seconds of dip-coating, there are large amounts of resol coated on the surface of Si/PVA nanofibers (inset of Figure 1(c)). The rapid and uniform formation of resol deposits on the Si/PVA nanofibers can be attributed to the high specific surface area $\left(156 \mathrm{~m}^{2} \mathrm{~g}^{-1}\right)$ and turbostratic structure of Si/PVA nanofibers, which can provide more active sites for deposition. Raman spectrum shown in Figure 1(e) confirms the characteristic of amorphous structure of Si/PVA nanofibers, which show a relatively high intensity ratio of disorder induced band (D-peak) and graphite band (Gpeak) $\left(I_{\mathrm{D}} / I_{\mathrm{G}}=1.77\right)$. Finally, hollow $\mathrm{Si} / \mathrm{C}$ composites were obtained by solidification and carbonization of Si/PVA-Resol composites. After the elaborate control of solidification and carbonization processes, original PVA located in core of
Si/PVA-Resol composites could be removed by decomposition, and solid resol shell will turn to tubular carbon and form triaxial interconnected hollow carbon nanofiber networks. This unique architecture can encapsulate Si nanoparticles into triaxial interconnected hollow carbon tubes and provide ample empty space around Si nanoparticles. Hence it can not only enhance electrical conductivity and stabilize solid electrolyte interface (SEI) but also allow for silicon expansion freely during electrochemical cycling, supporting a stable cycling of the entire electrode as well as high charge and discharge rates. The macrograph of the $\mathrm{H}-\mathrm{Si} / \mathrm{C}-3$ was shown in Figure 1(c). Apparently, H-Si/C-3 has reserved the freestanding membrane macrostructure. As for microstructure of $\mathrm{H}-\mathrm{Si} / \mathrm{C}-3$ (Figures $1(\mathrm{~d}$ ) and 2(b)), it can be seen that $\mathrm{H}-\mathrm{Si} / \mathrm{C}$ 3 exhibits triaxial interconnected fiber networks morphology, with diameters ranging from tens to hundreds of nanometers. The Si nanoparticles with diameters around 50 100 nm were encapsulated in hollow carbon fibers and the wall thickness of hollow fibers is around 10 20 nm. Moreover, to ascertain the silicon in the hollow $\mathrm{Si} / \mathrm{C}$ composites, $\mathrm{X}$-ray diffractions (XRD) were performed. As shown in Figure 1(f), the broad peaks of all samples with $2 \theta$ around $23^{\circ}$ demonstrate the existence of disordered amorphous carbon. Five obvious diffraction peaks with $28.4^{\circ}, 47.3^{\circ}, 56.1^{\circ}, 69.1^{\circ}$, and $76.4^{\circ}$ can be assigned to the pure crystalline silicon element, which represent (111), (220), (311), (400), and (311) planes of Si crystallites (JCPDS no. 27-1402), respectively. Furthermore, interestingly, for hollow $\mathrm{Si} / \mathrm{C}$ composites, characteristic peaks at $26.5^{\circ}$ appear which can be indexed to the (002) plane of graphite, and the intensity of diffraction peaks of it increases at higher concentration of dip solution, which exhibits the increase of carbon content in hollow Si/C composites [10].

Figures 2(a)-2(d) show the magnified SEM images of hollow Si/C composites. Triaxial interconnected nanofiber networks were obtained for all hollow $\mathrm{Si} / \mathrm{C}$ composites. The concentration increase of dip solution definitely affected the morphology of the resultant nanofiber networks. In the case of $\mathrm{H}-\mathrm{Si} / \mathrm{C}-1$, the tubular structure was broken and collapsed seriously on account of the lack of resol coating. With the increase of the dip solution concentration from 3\% to $10 \%$ for $\mathrm{H}-\mathrm{Si} / \mathrm{C}-3, \mathrm{H}-\mathrm{Si} / \mathrm{C}-5$, and $\mathrm{H}-\mathrm{Si} / \mathrm{C}-10$, it can be seen that the integrated nanofiber networks and the wall thickness of them become thicker. This phenomenon is also confirmed by TEM observation. In Figure 2(e), it is found that $\mathrm{H}$ $\mathrm{Si} / \mathrm{C}-1$ was a solid $\mathrm{Si} / \mathrm{C}$ nanofiber, and there was no residual space around the silicon nanoparticles. For $\mathrm{H}-\mathrm{Si} / \mathrm{C}-3, \mathrm{H}-$ $\mathrm{Si} / \mathrm{C}-5$, and H-Si/C-10 (Figures $2(\mathrm{f})-2(\mathrm{~h})$ ), they have typical tubular morphology and wall thickness arises apparently from around $20 \mathrm{~nm}$ for $\mathrm{H}-\mathrm{Si} / \mathrm{C}-3$ to around $100 \mathrm{~nm}$ for $\mathrm{H}$ $\mathrm{Si} / \mathrm{C}-10$. Furthermore, it can be seen from inset of Figures 2(g) and 2(h) that well-stacked sheets along the in-plane direction as well as the random orientations in the wall are observed indicating a graphitic shell for $\mathrm{H}-\mathrm{Si} / \mathrm{C}-5$ and $\mathrm{H}-\mathrm{Si} / \mathrm{C}-10$. This is in good agreement with the XRD analysis.

The carbon yield and silicon content of the hollow $\mathrm{Si} / \mathrm{C}$ composites were characterized by TGA. As shown in Figure 3(a), the final residual weight of the hollow Si/C composites at $600^{\circ} \mathrm{C}$ in $\mathrm{Ar}$ atmosphere increases with the increase of the concentration of dip solution. Figure 3(b) 


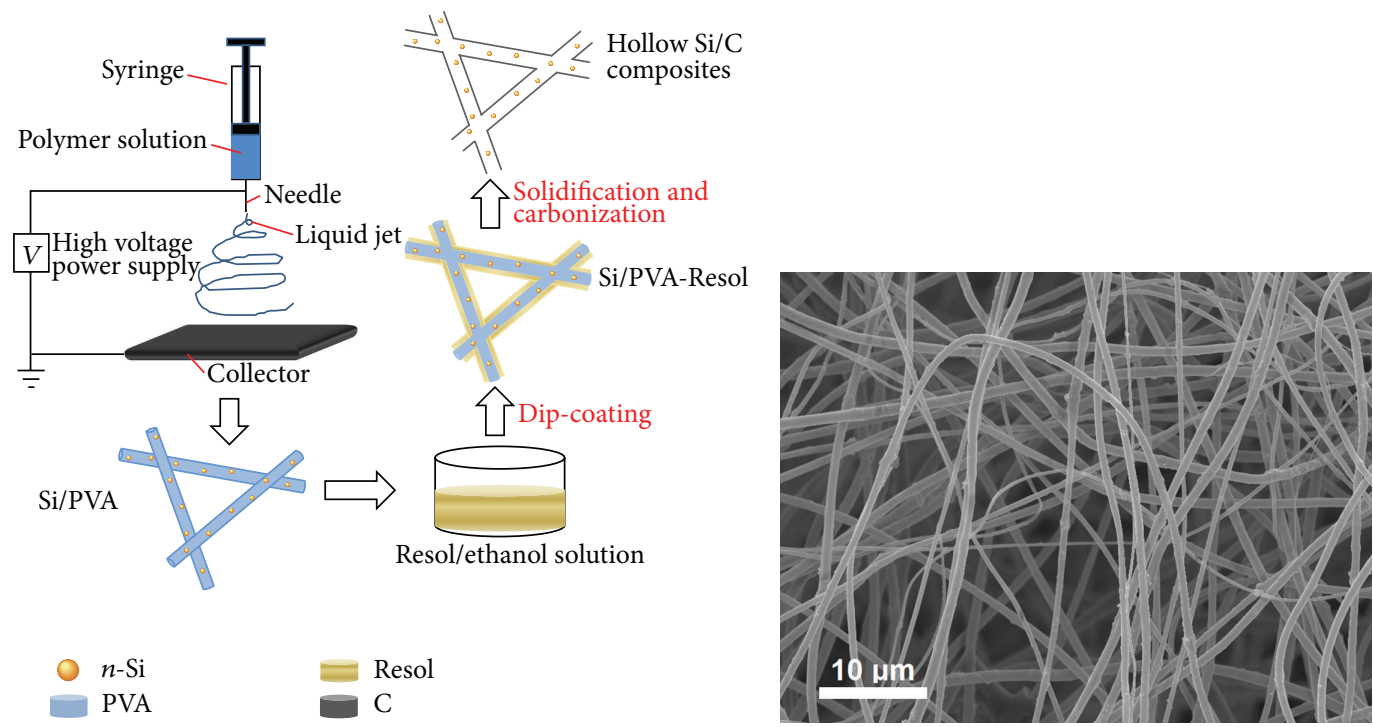

(a)

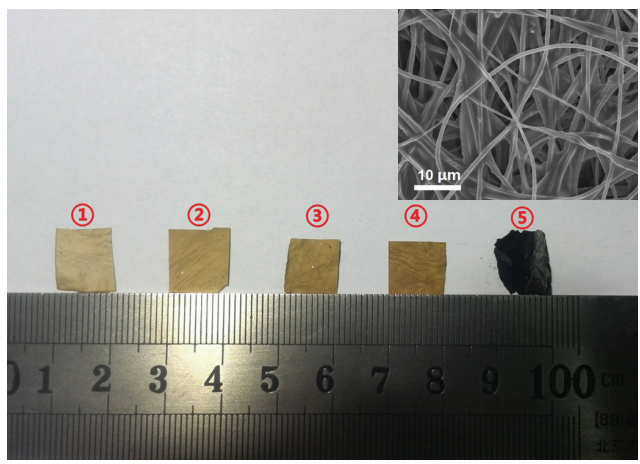

(c)

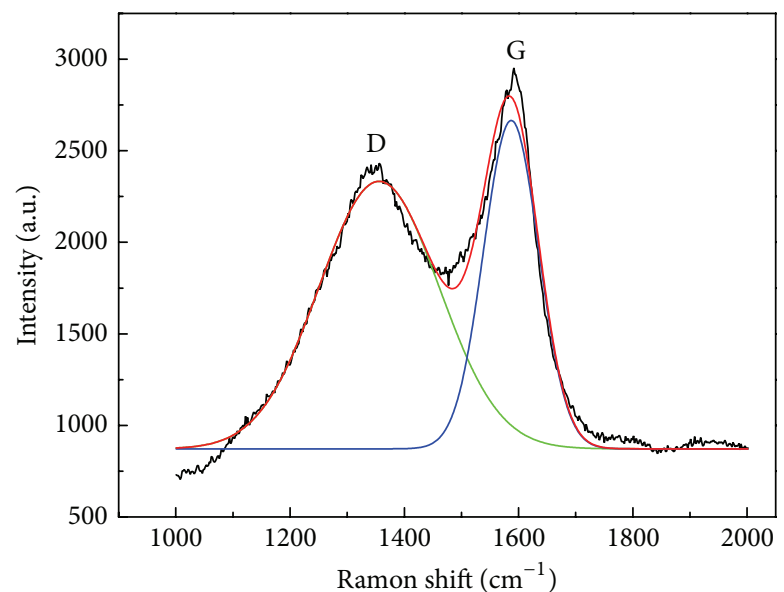

- Si/PVA
Peak D
_ Peak G

__ Peak sum

(e) (b)

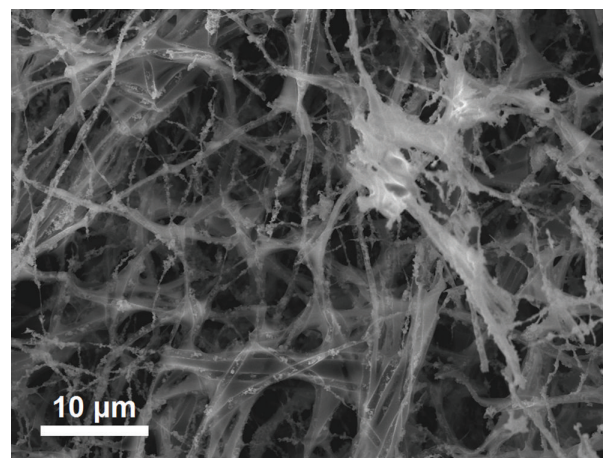

(d)

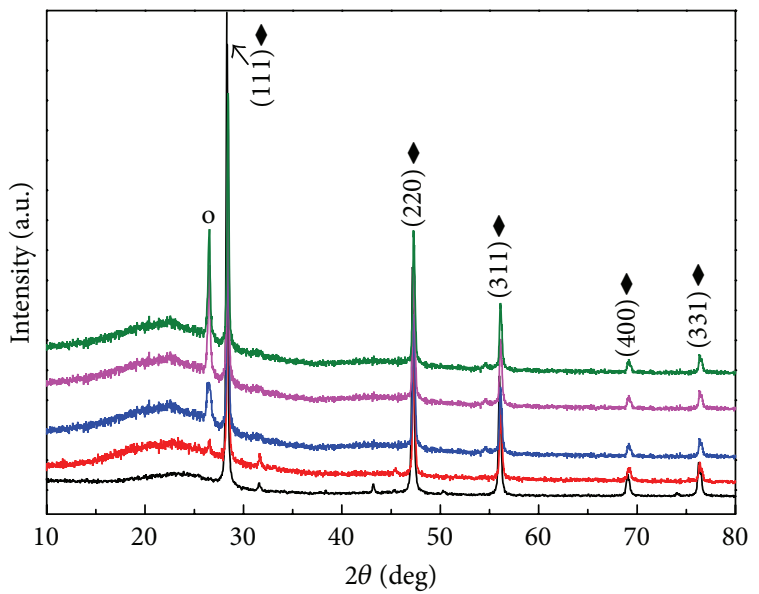

$\begin{array}{ll}- & \mathrm{Si} / \mathrm{PVA} \\ - & \mathrm{H}-\mathrm{Si} / \mathrm{C}-1 \\ - & \mathrm{H}-\mathrm{Si} / \mathrm{C}-3 \\ & \mathrm{H}-\mathrm{Si} / \mathrm{C}-5\end{array}$

H-Si/C-10

- Si: PDF27-1402

o Graphite: (002)

(f)

Figure 1: (a) Schematic illustration of the formation of the hollow Si/C nanofiber networks; (b) SEM image of Si/PVA nanofibers; (c) a macrograph of the Si/PVA-Resol composites after solidification and hollow Si/C composites (inset is SEM image of Si/PVA-Resol-3). (1) is Si/PVA-Resol-1, (2) is Si/PVA-Resol-3, (3) is Si/PVA-Resol-5, (4) is Si/PVA-Resol-10, and (5) is H-Si/C-3; (d) SEM image of H-Si/C-3; (e) Raman spectrum of the Si/PVA nanofibers; (f) XRD patterns of Si/PVA nanofibers and hollow Si/C composites. 


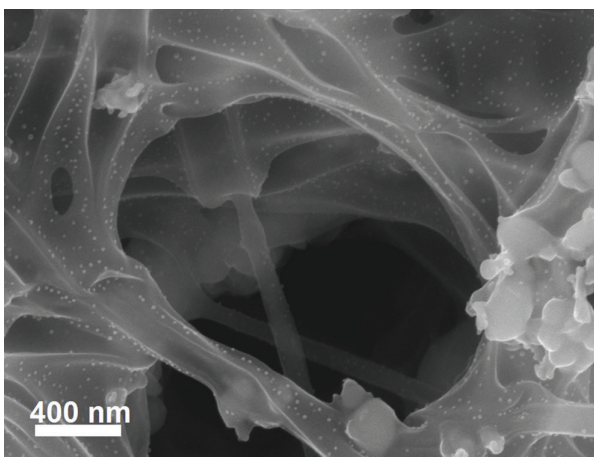

(a)

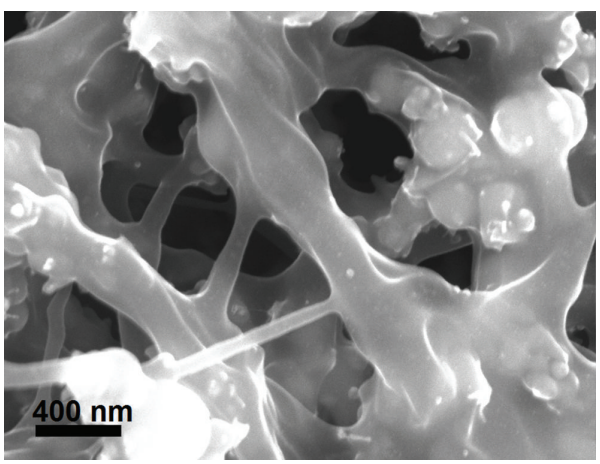

(c)

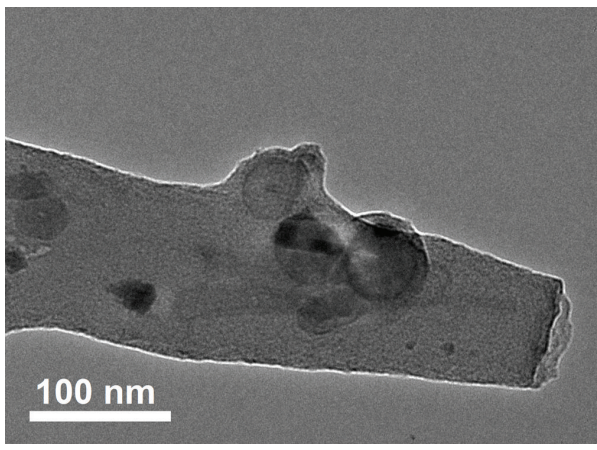

(e)

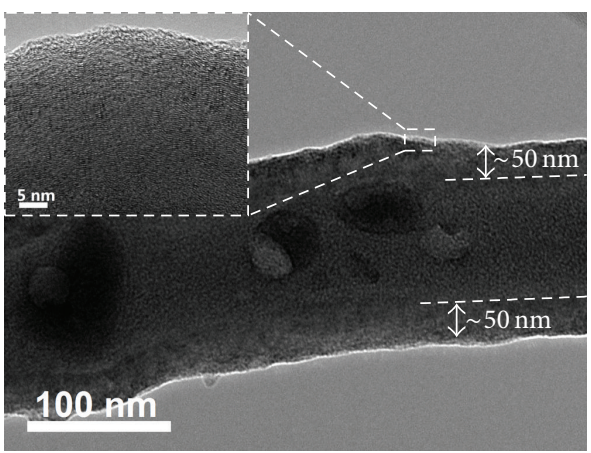

(g)

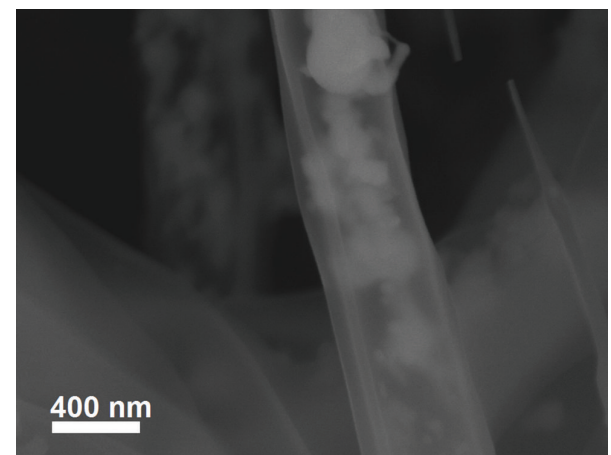

(b)

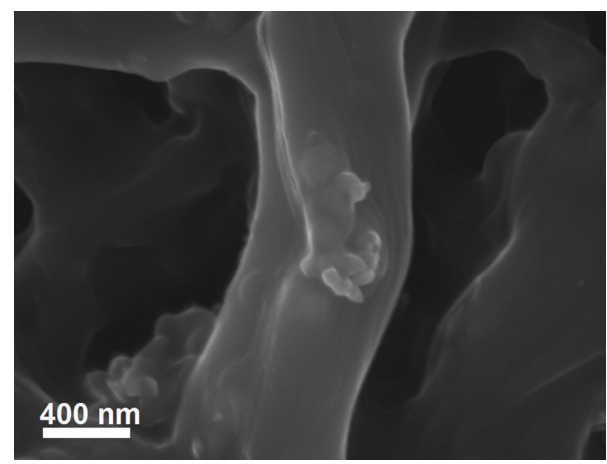

(d)

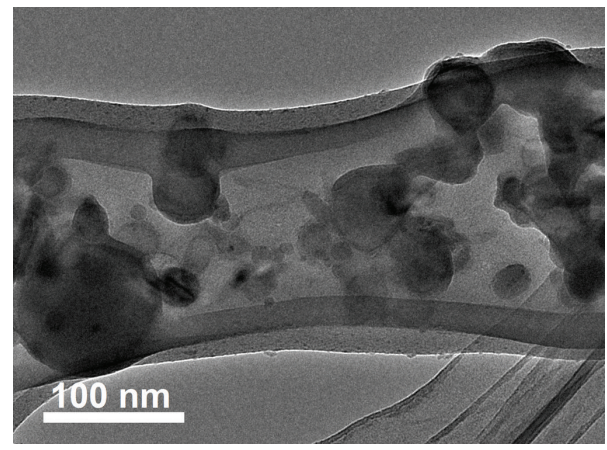

(f)

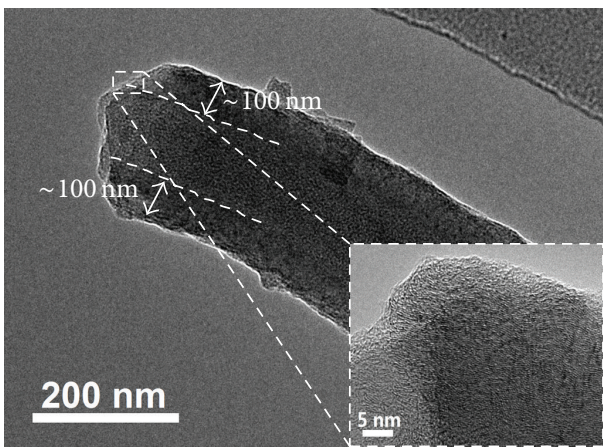

(h)

Figure 2: Magnified SEM images of hollow Si/C composites, (a) H-Si/C-1, (b) H-Si/C-3, (c) H-Si/C-5, and (d) H-Si/C-10. TEM images of hollow Si/C composites, (e) H-Si/C-1, (f) H-Si/C-3, (g) H-Si/C-5, and (h) H-Si/C-10 (insets in (g) and (h) are HRTEM images of H-Si/C-5 and $\mathrm{H}-\mathrm{Si} / \mathrm{C}-10$, resp.). 
TABLE 1: The physical and electrochemical properties of different hollow Si/C composite nanostructures.

\begin{tabular}{lcccccc}
\hline Sample & Si content (\%) & SSA $^{\mathrm{a}}\left(\mathrm{m}^{2} \mathrm{~g}^{-1}\right)$ & $\begin{array}{c}\text { Theoretical } \\
\text { capacity } \\
\left(\mathrm{mAh} \mathrm{g}^{-1}\right)\end{array}$ & $\begin{array}{c}\text { 1st cycle reversible } \\
\text { capacity }\left(\mathrm{mAh} \mathrm{g}^{-1}\right)\end{array}$ & $\begin{array}{c}\text { 1st cycle CE } \\
(\%)\end{array}$ & $\begin{array}{c}50 \text { th cycle reversible } \\
\text { capacity }\left(\mathrm{mAh} \mathrm{g}^{-1}\right)\end{array}$ \\
\hline $\mathrm{H}-\mathrm{Si} / \mathrm{C}-1$ & 17.3 & 177.3 & 1181 & 913 & 48 & 567 \\
$\mathrm{H}-\mathrm{Si} / \mathrm{C}-3$ & 13.0 & 273.7 & 1025 & 841 & 58 & 745 \\
$\mathrm{H}-\mathrm{Si} / \mathrm{C}-5$ & 9.3 & 332.8 & 889 & 626 & 50 & 652 \\
$\mathrm{H}-\mathrm{Si} / \mathrm{C}-10$ & 8.0 & 274.8 & 842 & 579 & 54 & 493 \\
\hline
\end{tabular}

${ }^{\text {a }}$ Specific surface area (SSA) was calculated by the Brunauer-Emmett-Teller (BET) method.

${ }^{\mathrm{b}}$ The columbic efficiency (CE).

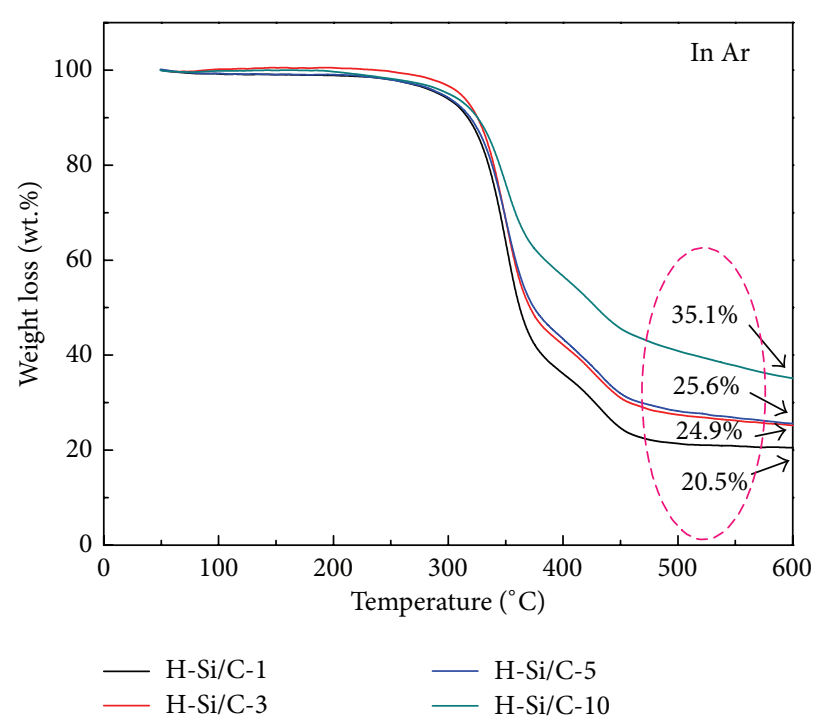

(a)

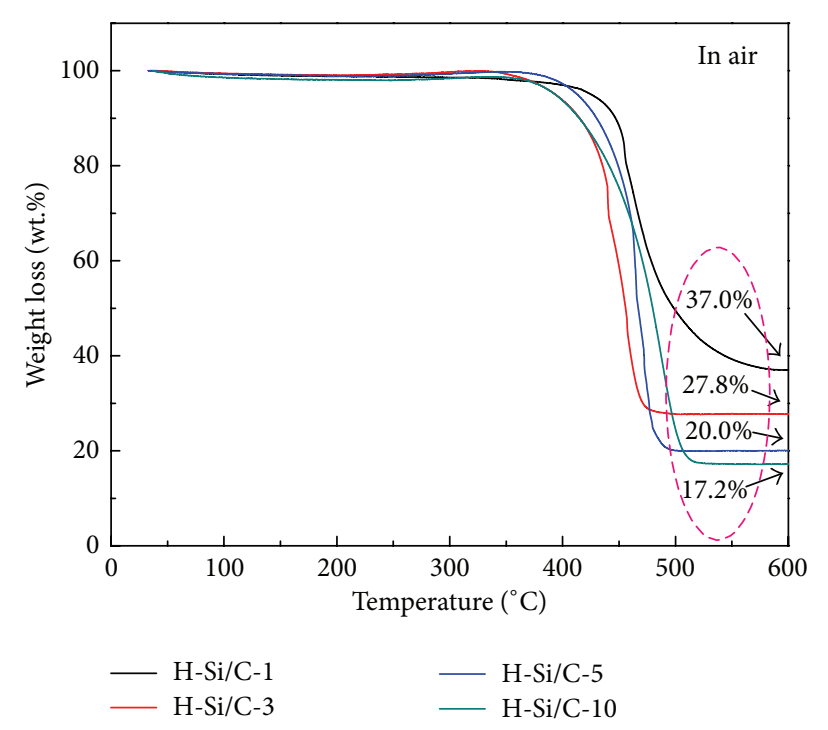

(b)

FIgURE 3: Thermogravimetric analysis (TGA) profiles of different hollow Si/C composites in (a) Ar and (b) air atmosphere.

presents the TGA results of the hollow $\mathrm{Si} / \mathrm{C}$ composite from $25^{\circ} \mathrm{C}$ to $600^{\circ} \mathrm{C}$ under air atmosphere. In air atmosphere, above $400^{\circ} \mathrm{C}$, the silicon can be oxidized to silica, while the carbon would be evolved to $\mathrm{CO}_{2}$. Thus the content of silicon can be calculated from the content of highly thermal stable $\mathrm{SiO}_{2}[3$, $26,37]$. The final results of silicon content were summarized in Table 1. Obviously, for increase of the relatively content of carbon, the content of silicon was decreased by increasing of the concentration of dip solution. These results suggested that we can effectively regulate the relatively content of carbon and silicon by changing the concentration of dip solution.

3.2. Electrochemical Evaluations. The electrochemical behaviors of hollow $\mathrm{Si} / \mathrm{C}$ composites were evaluated using deep galvanostatic charge/discharge cycles and cyclic voltammetry (CV) from 0.01 to $1.50 \mathrm{~V}$. The collected free-standing siliconencapsulated hollow carbon nanofiber networks were directly used as anodes in LIBs, without using copper current collector and adding any other polymeric binders or conductive additives. It could remarkably facilitate the high-speed electron transport, hold great potential to enhance the electrochemical performance, simplify the preparation process of electrode, and reduce the cost. The cycling performance of hollow $\mathrm{Si} / \mathrm{C}$ composites at a charge/discharge current density of $100 \mathrm{~mA} \mathrm{~g}^{-1}$ is illustrated in Figure 4(a). It is clear that $\mathrm{H}$ $\mathrm{Si} / \mathrm{C}-3$ shows the largest capacity and good cycling stability superior to the $\mathrm{H}-\mathrm{Si} / \mathrm{C}-1, \mathrm{H}-\mathrm{Si} / \mathrm{C}-5$, and $\mathrm{H}-\mathrm{Si} / \mathrm{C}-10$. And the first cycle reversible capacity was $841 \mathrm{mAh} \mathrm{g}^{-1}$ based on all the $\mathrm{Si}$ and carbon mass, which is more than twice that of traditional graphitic anodes $\left(372 \mathrm{mAh} \mathrm{g}^{-1}\right)$. Furthermore, H-Si/C3 showed an excellent cycling stability and discharge capacity retention of about $89 \%$ after 50 cycles, with $745 \mathrm{mAh} \mathrm{g}^{-1}$ in the 50th cycle. In addition, as deduced from Figure 4(a), with the increase of concentration of dip solution, the hollow $\mathrm{Si} / \mathrm{C}$ composites exhibit decreased first cycle reversible capacity. This can be attributed to the decrease of weight percentage of Si with the increase of concentration of dip solution. Based on the capacity from pure $\mathrm{Si}$ and carbon, the theoretical capacity $\left(C_{t}\right)$ of hollow $\mathrm{Si} / \mathrm{C}$ composites was calculated according to the following equation and the results were summarized in Table 1:

$$
C_{t}=C_{\mathrm{Si}} W_{\mathrm{Si}}+C_{\mathrm{C}} W_{\mathrm{C}}
$$

where $C_{\mathrm{Si}}$ and $C_{\mathrm{C}}$ denote the theoretical capacity of $\mathrm{Si}$ $\left(4200 \mathrm{mAh} \mathrm{g}^{-1}\right)$ and resol-derived carbon $\left(550 \mathrm{mAh} \mathrm{g}^{-1}\right)$ [43], respectively. $W_{\mathrm{Si}}$ and $W_{\mathrm{C}}$ are the weight percentages of $\mathrm{Si}$ 


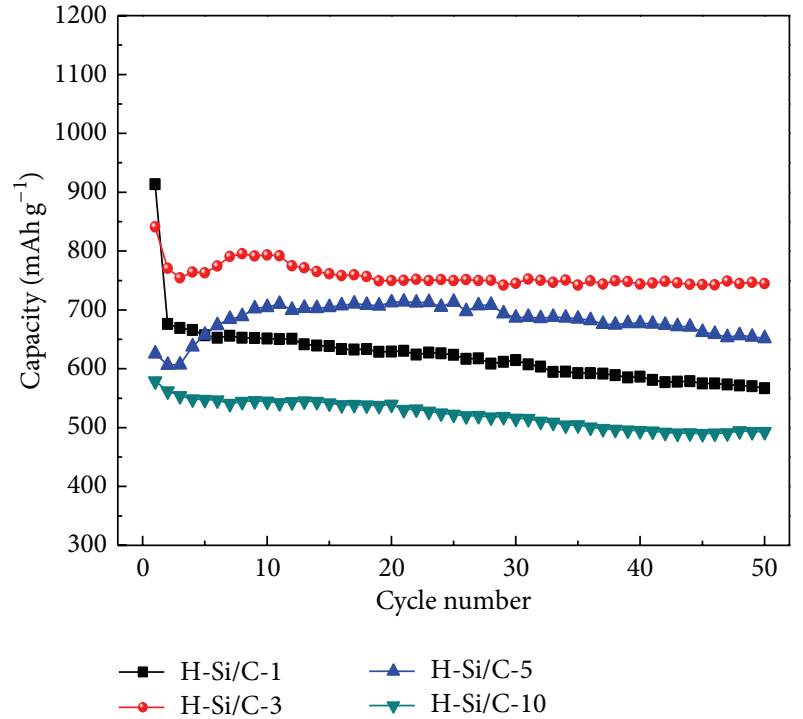

(a)

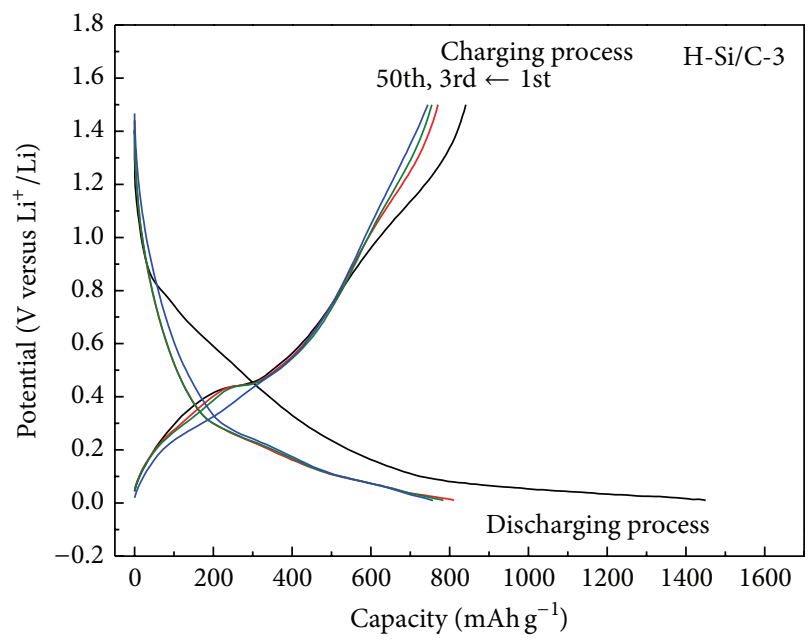

(c)

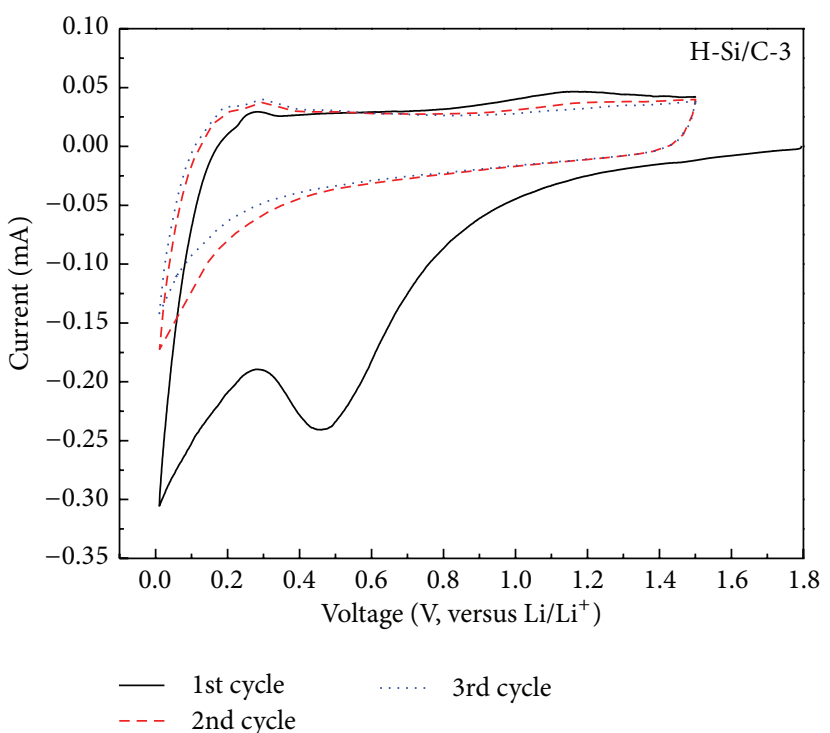

(b)

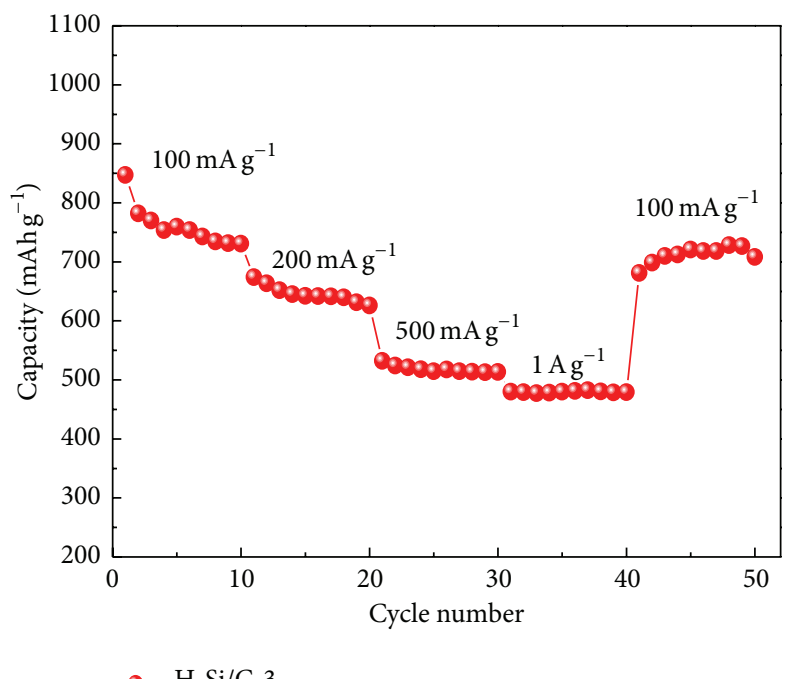

(d)

FIgure 4: (a) Cycling performance of hollow Si/C composites; (b) cyclic voltammograms, (c) charge/discharge curves, and (d) rate performance of $\mathrm{H}-\mathrm{Si} / \mathrm{C}-3$.

and carbon, respectively. The first cycle reversible capacity of $\mathrm{H}-\mathrm{Si} / \mathrm{C}-1, \mathrm{H}-\mathrm{Si} / \mathrm{C}-3, \mathrm{H}-\mathrm{Si} / \mathrm{C}-5$, and $\mathrm{H}-\mathrm{Si} / \mathrm{C}-10$ was about $77 \%$, $82 \%, 70 \%$, and $69 \%$ of their theoretical capacity, respectively.

These results indicate that hollow $\mathrm{Si} / \mathrm{C}$ composites, especially $\mathrm{H}-\mathrm{Si} / \mathrm{C}-3$, arouse the electrochemical potential of $\mathrm{Si}$ efficiently as well as improving the structural stability of the $\mathrm{Si}$-containing anode materials. $\mathrm{H}-\mathrm{Si} / \mathrm{C}-1$ shows the highest theoretical capacity and initial reversible capacity but a worse cycling performance than $\mathrm{H}-\mathrm{Si} / \mathrm{C}-3, \mathrm{H}-\mathrm{Si} / \mathrm{C}-5$, and $\mathrm{H}-$ $\mathrm{Si} / \mathrm{C}-10$. The 50th cycle discharge capacity of $\mathrm{H}-\mathrm{Si} / \mathrm{C}-1$ was $567 \mathrm{mAh} \mathrm{g}^{-1}$, yielding capacity retention only about $62 \%$. It is because the tubular nanostructure of $\mathrm{H}-\mathrm{Si} / \mathrm{C}-1$ was crumpled up due to lack of resol, becoming solid $\mathrm{Si} / \mathrm{C}$ nanofibers, thus no residual space around the silicon nanoparticles for expansion during charge-discharge process. In a word, the concentration of dip solution has an optimum value for hollow $\mathrm{Si} / \mathrm{C}$ composites. If the concentration of dip solution is too high, it will cause the decrease of $\mathrm{Si}$ weight percentage and the increase of the carbon wall thickness accordingly. On the contrary, the decrease of the dip solution concentration will lead to the collapse of the tubular nanostructure due to the lack of enough resol. Therefore, we can effectively coordinate the structure and Si content of hollow $\mathrm{Si} / \mathrm{C}$ composites by merely varying the concentration of dip solution to obtain good electrochemical performance.

Figure 4(b) shows the CVs for the 1st, 2nd, and 3rd cycles of $\mathrm{H}-\mathrm{Si} / \mathrm{C}-3$ electrode in lithium ion half cells, in which a lithium foil was used as the counter and reference 
electrode. In the first cycle, a broad peak ranging from 0.3 to $0.8 \mathrm{~V}$ in the reduction process, which disappears at the second and third cycle, corresponds to SEI formation on the electrode surface due to electrolyte decomposition. The distinct peak around $0.1 \mathrm{~V}$ demonstrates the alloying process of Si nanoparticles with lithium ions. In the oxidation process, a broad oxidation peak which corresponds to the lithium extraction from $\mathrm{H}-\mathrm{Si} / \mathrm{C}-3$ is located at $0.2-0.4 \mathrm{~V}$ and becomes more distinct after the first cycle [10]. Figure 4(c) shows the typical galvanostatic charge/discharge curves of $\mathrm{H}-\mathrm{Si} / \mathrm{C}-3$ anode for the initial three cycles and 50th cycle at a current density of $100 \mathrm{mAg}^{-1}$. The voltage has a sharp drop to a relatively potential plateau at $0.3-0.8 \mathrm{~V}$ in the first cycle, which is associated with the formation of solid electrolyte interphase (SEI) film on the electrode due to the decomposition of electrolyte $[26,36,37]$. The initial discharge capacity of $\mathrm{H}-\mathrm{Si} / \mathrm{C}-3$ is as high as $1450 \mathrm{mAh} \mathrm{g}^{-1}$ and yields $609 \mathrm{mAh} \mathrm{g}^{-1}$ of irreversible charge capacity. The columbic efficiency of it is $58 \%$. The large initial irreversible capacity can be mainly ascribed to the formation of SEI layer at the surface of $\mathrm{H}-\mathrm{Si} / \mathrm{C}-3$ and/or the irreversible side reactions with the electrolyte [36]. Nevertheless, the columbic efficiency in the second cycle and thereafter increases over $95 \%$ and a stable capacity is achieved. The rate capability of $\mathrm{H}-\mathrm{Si} / \mathrm{C}-3$ was further investigated. As depicted in Figure 4(d), H-Si/C3 anode delivers a capacity of $847 \mathrm{mAh} \mathrm{g}^{-1}$ at $100 \mathrm{~mA} \mathrm{~g}^{-1}$, $674 \mathrm{mAh} \mathrm{g}^{-1}$ at $200 \mathrm{~mA} \mathrm{~g}^{-1}, 532 \mathrm{mAh} \mathrm{g}^{-1}$ at $500 \mathrm{~mA} \mathrm{~g}^{-1}$, and $480 \mathrm{mAh} \mathrm{g}^{-1}$ at $1000 \mathrm{mAg}^{-1}$. The capacity can be recovered to $681 \mathrm{mAh} \mathrm{g}^{-1}$ when the current density is turned back to $100 \mathrm{mAg}^{-1}$, indicating good cycling stability and rate capability.

The outstanding electrochemical properties of siliconencapsulated hollow carbon nanofiber networks can be attributed to its unique 3D interconnected tubular hollow nanostructure encapsulated silicon nanoparticles with ambient empty space. Firstly, the hollow Si/C composites electrode contained plenty of void spaces around Si nanoparticle, which can effectively prevent damage of whole electrode by allowing Si nanoparticle to expand freely without mechanical constraint during lithiation process, enabling a stable electrochemical cycle performance and excellent rate performance. Secondly, the triaxial interconnected conducting nanofibrous networks constituted by carbon tubes and lack of insulating binders can remarkably enhance the conductivity of electrode, which will ensure a fast electron transfer for rapid Faradic reaction, and shorten the ionic transport length as well. Lastly, the encapsulation with hollow carbon nanofibers defends silicon nanoparticles against direct contact with the electrolyte; thus stable SEI can be obtained during cycling.

\section{Conclusions}

Silicon-encapsulated hollow carbon nanofiber networks with plenty of space around the Si nanoparticles were successfully prepared by dip-coating resol on the surface of electrospinning Si/PVA nanofibers and the subsequent solidification and carbonization processes. By simply varying the concentration of dip solution, we can effectively tune the structure and $\mathrm{Si}$ content of hollow $\mathrm{Si} / \mathrm{C}$ composites and acquire prominent electrochemical performance. As binder-free anodes for LIBs, $\mathrm{H}-\mathrm{Si} / \mathrm{C}-3$ shows a high capacity of $841 \mathrm{mAh} \mathrm{g}^{-1}$ in the first cycle, prominent rate capability, and excellent cycling stability. The discharge capacity retention of $\mathrm{H}-\mathrm{Si} / \mathrm{C}-3$ was $\sim 90 \%$, with $745 \mathrm{mAh} \mathrm{g}^{-1}$ after 50 cycles. It demonstrates that the hollow $\mathrm{Si} / \mathrm{C}$ composites are very promising as alternative anode candidates for high-performance LIBs. Furthermore, this study also provides a new insight that the triaxial interconnected tubular hollow nanostructure is a good solution for other LIBs electrodes that suffer from volume expansion or unstable interfacial properties with electrolytes, such as $\mathrm{Sn}$ and metal oxides anodes.

\section{Conflict of Interests}

The authors declare that there is no conflict of interests regarding the publication of this paper.

\section{Acknowledgments}

The authors thank the financial supports from the National Natural Science Foundation of China (no. 51232005) and 973 program of China (no. 2014CB932401). This work is also supported by Ministry of Science and Technology (MOST) of China under Grant 2010DFA72760, Collaboration on cutting-edge technology development of electric vehicle.

\section{References}

[1] J. R. Szczech and S. Jin, "Nanostructured silicon for high capacity lithium battery anodes," Energy and Environmental Science, vol. 4, no. 1, pp. 56-72, 2011.

[2] H. Wu, G. Zheng, N. Liu, T. J. Carney, Y. Yang, and Y. Cui, "Engineering empty space between Si nanoparticles for lithiumion battery anodes," Nano Letters, vol. 12, no. 2, pp. 904-909, 2012.

[3] T. H. Hwang, Y. M. Lee, B.-S. Kong, J.-S. Seo, and J. W. Choi, "Electrospun core-shell fibers for robust silicon nanoparticlebased lithium ion battery anodes," Nano Letters, vol. 12, no. 2 , pp. 802-807, 2012.

[4] H. Li, X. Huang, L. Chen, Z. Wu, and Y. Liang, "High capacity nano-Si composite anode material for lithium rechargeable batteries," Electrochemical and Solid-State Letters, vol. 2, no. 11, pp. 547-549, 1999.

[5] N. Dimov, S. Kugino, and M. Yoshio, "Carbon-coated silicon as anode material for lithium ion batteries: advantages and limitations," Electrochimica Acta, vol. 48, no. 11, pp. 1579-1587, 2003.

[6] G. X. Wang, J. H. Ahn, J. Yao, S. Bewlay, and H. K. Liu, "Nanostructured Si-C composite anodes for lithium-ion batteries," Electrochemistry Communications, vol. 6, no. 7, pp. 689-692, 2004.

[7] S.-H. Ng, J. Wang, D. Wexler, K. Konstantinov, Z.-P. Guo, and H.-K. Liu, "Highly reversible lithium storage in spheroidal carbon-coated silicon nanocomposites as anodes for lithiumion batteries," Angewandte Chemie-International Edition, vol. 45, no. 41, pp. 6896-6899, 2006. 
[8] H. Uono, B.-C. Kim, T. Fuse, M. Ue, and J.-I. Yamaki, "Optimized structure of silicon/carbon/graphite composites as an anode material for Li-ion matteries," Journal of the Electrochemical Society, vol. 153, no. 9, pp. A1708-A1713, 2006.

[9] H. M. Jeong, S. Y. Lee, W. H. Shin et al., "Silicon@porous nitrogen-doped carbon spheres through a bottom-up approach are highly robust lithium-ion battery anodes," RSC Advances, vol. 2, no. 10, pp. 4311-4317, 2012.

[10] Y. Yong and L.-Z. Fan, "Silicon/carbon nanocomposites used as anode materials for lithium-ion batteries," Ionics, vol. 19, no. 11, pp. 1545-1549, 2013.

[11] H. Kim, B. Han, J. Choo, and J. Cho, "Three-dimensional porous silicon particles for use in high-performance lithium secondary batteries," Angewandte Chemie-International Edition, vol. 47, no. 52, pp. 10151-10154, 2008.

[12] A. Magasinski, P. Dixon, B. Hertzberg, A. Kvit, J. Ayala, and G. Yushin, "High-performance lithium-ion anodes using a hierarchical bottom-up approach," Nature Materials, vol. 9, no. 4, pp. 353-358, 2010.

[13] S. Bourderau, T. Brousse, and D. M. Schleich, "Amorphous silicon as a possible anode material for Li-ion batteries," Journal of Power Sources, vol. 81-82, pp. 233-236, 1999.

[14] L. Y. Beaulieu, K. W. Eberman, R. L. Turner, L. J. Krause, and J. R. Dahna, "Colossal reversible volume changes in lithium alloys," Electrochemical and Solid-State Letters, vol. 4, no. 9, pp. A137A140, 2001.

[15] J. Graetz, C. C. Ahn, R. Yazami, and B. Fultz, "Highly reversible lithium storage in nanostructured silicon," Electrochemical and Solid-State Letters, vol. 6, no. 9, pp. A194-A197, 2003.

[16] J. P. Maranchi, A. F. Hepp, and P. N. Kumta, "High capacity, reversible silicon thin-film anodes for lithium-ion batteries," Electrochemical and Solid-State Letters, vol. 6, no. 9, pp. A198A201, 2003.

[17] J. P. Maranchi, A. F. Hepp, A. G. Evans, N. T. Nuhfer, and P. N. Kumta, "Interfacial properties of the a-SiCu: active-inactive thin-film anode system for lithium-ion batteries," Journal of the Electrochemical Society, vol. 153, no. 6, pp. A1246-A1253, 2006.

[18] A. A. Arie, J. O. Song, and J. K. Lee, "Structural and electrochemical properties of fullerene-coated silicon thin film as anode materials for lithium secondary batteries," Materials Chemistry and Physics, vol. 113, no. 1, pp. 249-254, 2009.

[19] M.-H. Park, M. G. Kim, J. Joo et al., "Silicon nanotube battery anodes," Nano Letters, vol. 9, no. 11, pp. 3844-3847, 2009.

[20] T. Song, J. Xia, J.-H. Lee et al., "Arrays of sealed silicon nanotubes as anodes for lithium ion batteries," Nano Letters, vol. 10, no. 5, pp. 1710-1716, 2010.

[21] J.-K. Yoo, J. Kim, Y. S. Jung, and K. Kang, "Scalable fabrication of silicon nanotubes and their application to energy storage," Advanced Materials, vol. 24, no. 40, pp. 5452-5456, 2012.

[22] C. K. Chan, H. Peng, G. Liu et al., "High-performance lithium battery anodes using silicon nanowires," Nature Nanotechnology, vol. 3, no. 1, pp. 31-35, 2008.

[23] J. L. Gómez-Cámer, J. Morales, and L. Sánchez, "Anchoring Si nanoparticles to carbon nanofibers: an efficient procedure for improving Si performance in Li batteries," Journal of Materials Chemistry, vol. 21, no. 3, pp. 811-818, 2011.

[24] T. Song, D. H. Lee, M. S. Kwon et al., "Silicon nanowires with a carbon nanofiber branch as lithium-ion anode material," Journal of Materials Chemistry, vol. 21, no. 34, pp. 12619-12621, 2011.
[25] K. Fu, L. Xue, O. Yildiz et al., "Effect of CVD carbon coatings on Si@CNF composite as anode for lithium-ion batteries," Nano Energy, vol. 2, no. 5, pp. 976-986, 2013.

[26] X. Fan, L. Zou, Y.-P. Zheng, F.-Y. Kang, and W.-C. Shen, "Electrospinning preparation of nanosilicon/disordered carbon composite as anode materials in li-ion battery," Electrochemical and Solid-State Letters, vol. 12, no. 10, pp. A199-A201, 2009.

[27] L. Ji and X. Zhang, "Fabrication of porous carbon/Si composite nanofibers as high-capacity battery electrodes," Electrochemistry Communications, vol. 11, no. 6, pp. 1146-1149, 2009.

[28] L. Ji, K.-H. Jung, A. J. Medford, and X. Zhang, "Electrospun polyacrylonitrile fibers with dispersed $\mathrm{Si}$ nanoparticles and their electrochemical behaviors after carbonization," Journal of Materials Chemistry, vol. 19, no. 28, pp. 4992-4997, 2009.

[29] L. Ji and X. Zhang, "Electrospun carbon nanofibers containing silicon particles as an energy-storage medium," Carbon, vol. 47, no. 14, pp. 3219-3226, 2009.

[30] L. Wang, C. X. Ding, L. C. Zhang et al., "A novel carbonsilicon composite nanofiber prepared via electrospinning as anode material for high energy-density lithium ion batteries," Journal of Power Sources, vol. 195, no. 15, pp. 5052-5056, 2010.

[31] S. Y. Kim, B.-H. Kim, and K. S. Yang, "Preparation and electrochemical characteristics of a polyvinylpyrrolidone-stabilized $\mathrm{Si}$ /carbon composite nanofiber anode for a lithium ion battery," Journal of Electroanalytical Chemistry, vol. 705, pp. 52-56, 2013.

[32] Y. Li, B. Guo, L. Ji et al., "Structure control and performance improvement of carbon nanofibers containing a dispersion of silicon nanoparticles for energy storage," Carbon, vol. 51, no. 1, pp. 185-194, 2013.

[33] Y. Li, G. Xu, L. Xue et al., "Enhanced rate capability by employing carbon nanotube-loaded electrospun Si/C composite nanofibers as binder-free anodes," Journal of the Electrochemical Society, vol. 160, no. 3, pp. A528-A534, 2013.

[34] L. Xue, K. Fu, Y. Li et al., "Si/C composite nanofibers with stable electric conductive network for use as durable lithiumion battery anode," Nano Energy, vol. 2, no. 3, pp. 361-367, 2013.

[35] H. Wu, G. Chan, J. W. Choi et al., "Stable cycling of double-walled silicon nanotube battery anodes through solidelectrolyte interphase control," Nature Nanotechnology, vol. 7, no. 5, pp. 309-314, 2012.

[36] W. Jigging, Y. Yan, G. Lin, W. Chunlei, T. Kun, and J. Maier, "Highly reversible lithium storage in $\mathrm{Si}$ (core)-hollow carbon nanofibers (sheath) nanocomposites," Nanoscale, vol. 5, no. 7, pp. 2647-2650, 2013.

[37] J. Kong, W. A. Yee, Y. Wei et al., "Silicon nanoparticles encapsulated in hollow graphitized carbon nanofibers for lithium ion battery anodes," Nanoscale, vol. 5, no. 7, pp. 2967-2973, 2013.

[38] H. Kim and J. Cho, "Superior lithium electroactive mesoporous Si@Carbon core-shell nanowires for lithium battery anode material," Nano Letters, vol. 8, no. 11, pp. 3688-3691, 2008.

[39] L.-F. Cui, R. Ruffo, C. K. Chan, H. Peng, and Y. Cui, "Crystallineamorphous core-shell silicon nanowires for high capacity and high current battery electrodes," Nano Letters, vol. 9, no. 1, pp. 491-495, 2009.

[40] L.-F. Cui, Y. Yang, C.-M. Hsu, and C. Yi, "Carbon-silicon Core-shell nanowires as high capacity electrode for lithium lon batteries," Nano Letters, vol. 9, no. 9, pp. 3370-3374, 2009.

[41] G. K. Simon, B. Maruyama, M. F. Durstock, D. J. Burton, and T. Goswami, "Silicon-coated carbon nanofiber hierarchical nanostructures for improved lithium-ion battery anodes," Journal of Power Sources, vol. 196, no. 23, pp. 10254-10257, 2011. 
[42] B.-S. Lee, S.-B. Son, K.-M. Park et al., "Fabrication of Si core/C shell nanofibers and their electrochemical performances as a lithium-ion battery anode," Journal of Power Sources, vol. 206, pp. 267-273, 2012.

[43] T. Zheng, Q. Zhong, and J. R. Dahn, "High-capacity carbons prepared from phenolic resin for anodes of lithium-ion batteries," Journal of the Electrochemical Society, vol. 142, no. 11, pp. L211-L214, 1995. 

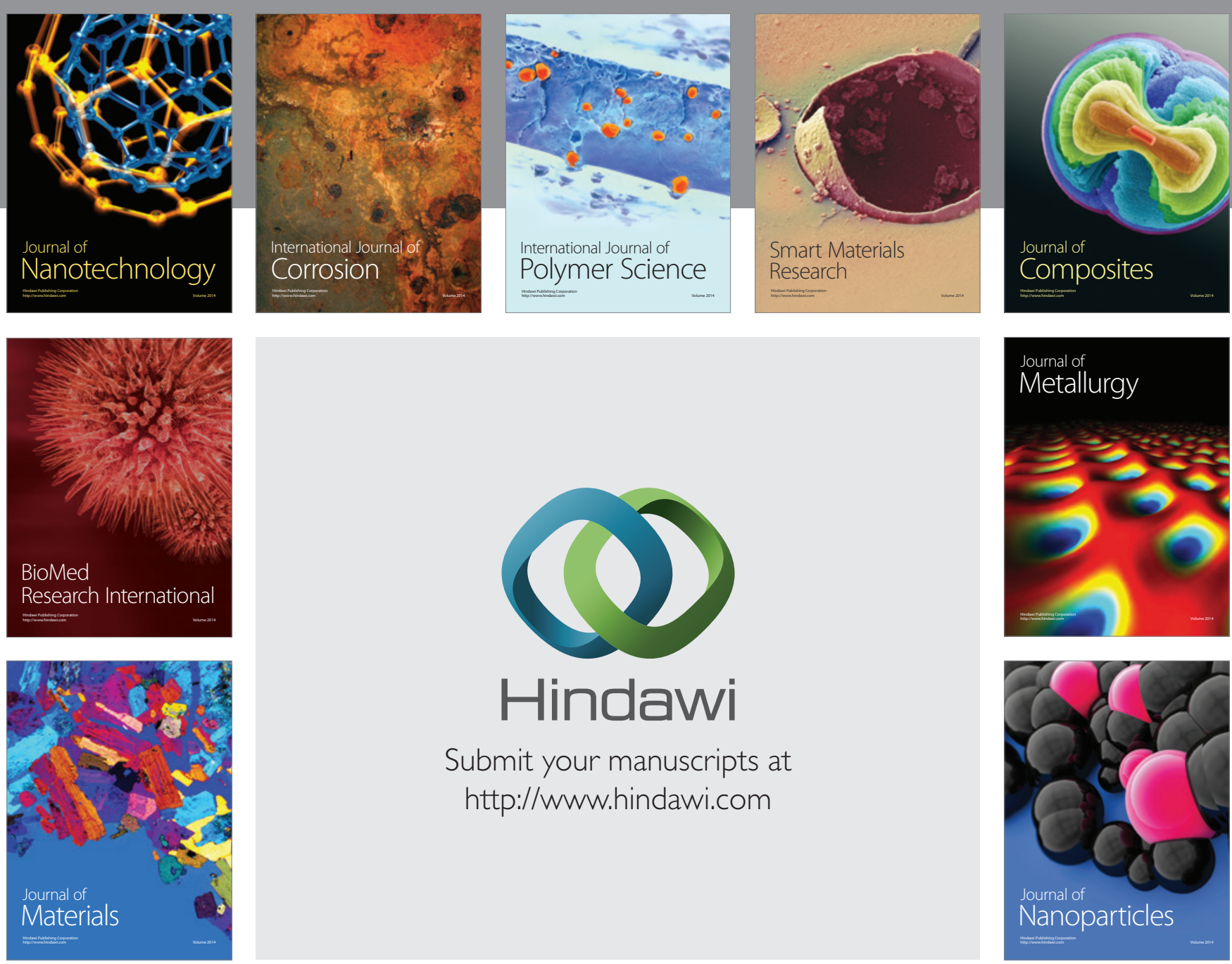

Submit your manuscripts at http://www.hindawi.com
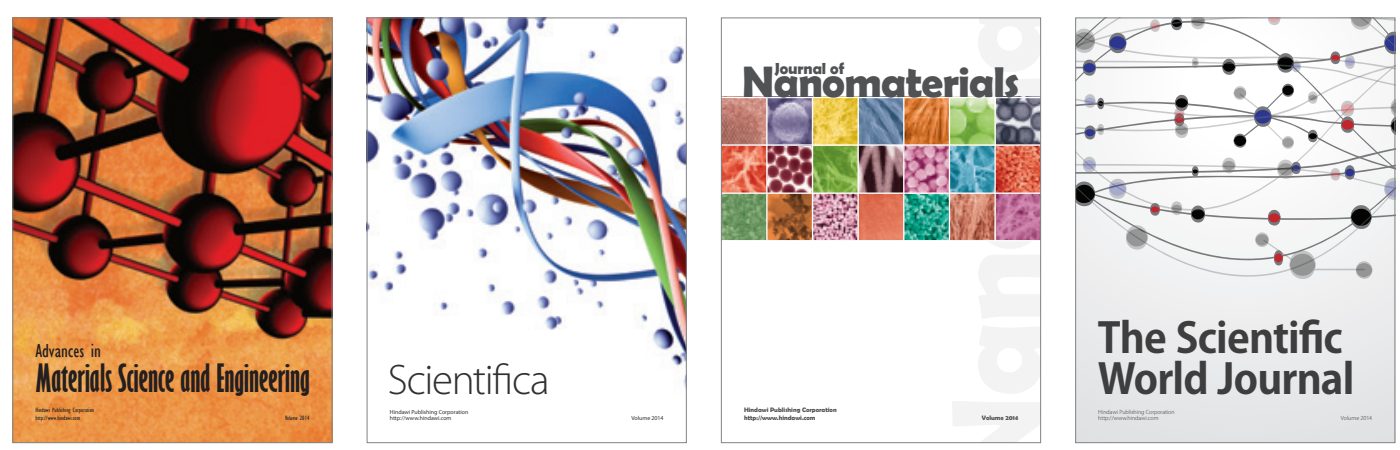

\section{The Scientific World Journal}
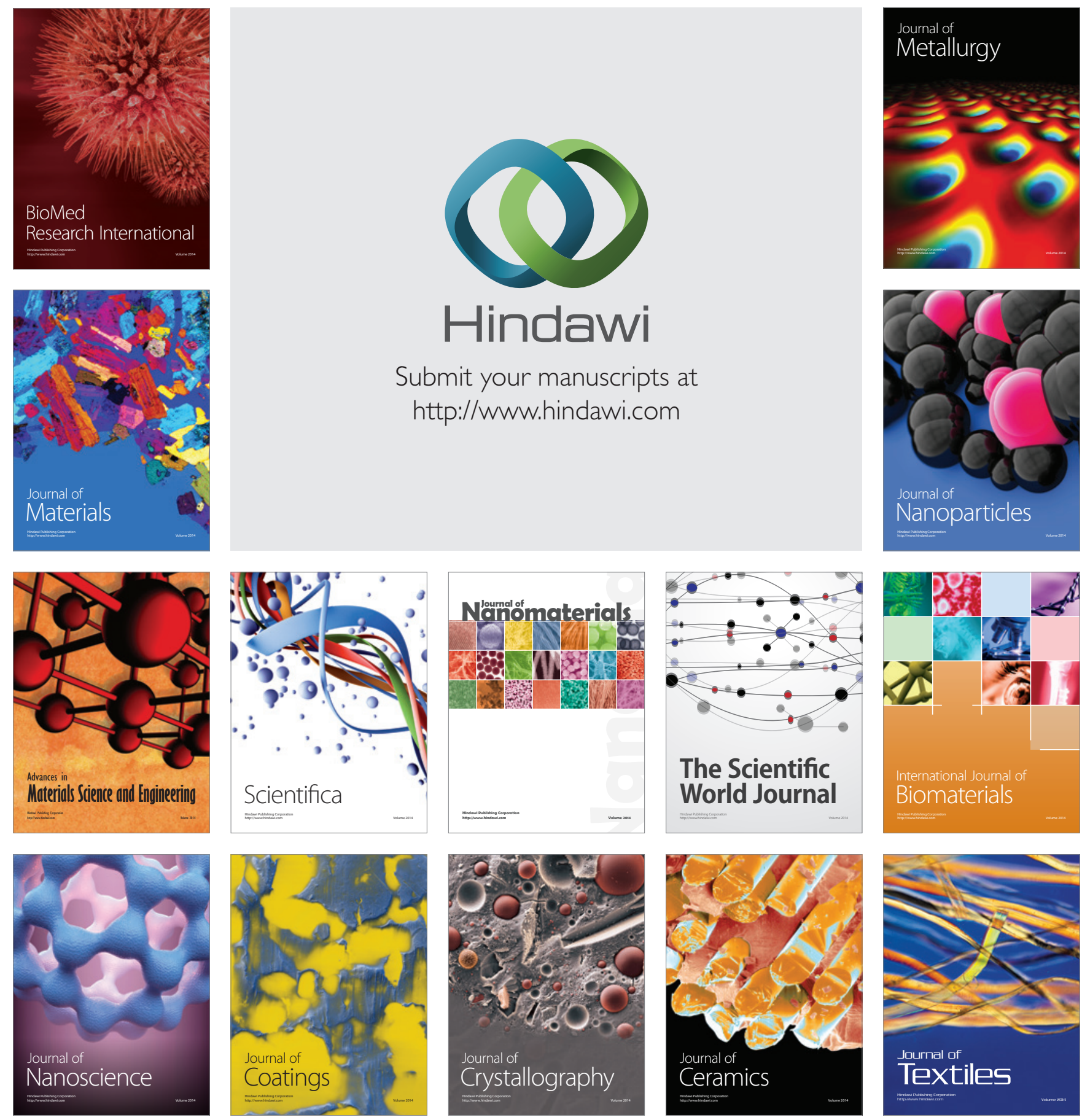